Malignant neoplasms of the larynx are divided into epithelial and non-epithelial. Non-epithelial neoplasms include, among others, mesenchymal chondrosarcomas and osteosarcomas. Few cases of laryngeal osteosarcomas described in the literature were usually treated by surgery without the need to use adjuvant radio- or chemotherapy. Few authors propose the initial application of radiotherapy or high-dose chemotherapy. Our study presents a very rare case of a woman treated due to laryngeal osteosarcoma. We have also presented diagnostic difficulties preceding a decision to perform radical surgery. The patient had been eligible for radical surgical treatment, even though there were no features of malignancy in a histopathological examination of the biopsy material. Complete laryngectomy was carried out without the surgery of the cervical lymphatic system. Laryngeal osteosarcoma was diagnosed based on the postoperative histopatholog ical examination using vimentin and Ki67. The patient remains under the care of the Otolaryngology and Laryngological Oncology Department and Oncology Centre in Bydgoszcz. There were no reports on local recurrence or distant metastases during regular check-ups.

Key words: osteosarcoma, larynx, treatment, oncology, DOI: $10.5114 /$ wo.2015.52659

\section{Osteosarcoma of the larynx}

\author{
Piotr Sawicki ${ }^{1}$, Wojciech Każmierczak ${ }^{1}$, Łukasz Szylberg ${ }^{2}$, Andrzej Marszałek ${ }^{2,3}$
}

${ }^{1}$ Chair and Clinic of Otolaryngology and Laryngological Oncology, Collegium Medicum in Bydgoszcz, Nicolaus Copernicus University in Torun, Poland

2Department of Clinical Pathomorphology, Collegium Medicum in Bydgoszcz,

Nicolaus Copernicus University in Torun, Poland

${ }^{3}$ Department of Clinical Pathomorphology, Poznan University of Medical Sciences,

Poznan, Poland

\section{Introduction}

Malignant laryngeal tumours can be divided into epithelial and non-epithelial types. Among the latter, sarcomas may be distinguished, which not only have a different origin (mesenchymal), but also different pathogenesis [1-3]. In the analysed literature, the authors unanimously emphasise the fact that there is no correlation between smoking and the occurrence of this relatively rare group of tumours [4-7]. Among the most frequently listed aetiological factors, aromatic hydrocarbons, ionizing radiation, and oncogenic viruses are cited [8-10]. The multitude of non-epithelial tumours requires a thorough diagnostic imaging and a highly specialised histopathological analysis along with determination of the vimentin/actin/desmin pattern [8]. Laryngeal osteosarcoma is an extremely rare tumour of the sarcoma group, described in very few case studies [3, 11]. It was described for the first time in 1966 by Sprinkle et al. [12].

Diagnostic and histopathological imaging in the case of osteosarcoma may be unclear and poses difficulties in preoperative assessment of tumour properties [13]. Osteomas, chondromas, and intermediate forms of benign laryngeal tumours are indications for therapy due to their local malignancy and the potential presence of a sarcoma component within the tumour [8, 14]. Primary osteosarcoma occurs more frequently in men in their $5^{\text {th }}$ to $7^{\text {th }}$ decade of life, and its first symptom is usually dysphonia gradually developing into stridor $[9,10,15]$. Despite the lack of prospective studies regarding the types of laryngeal osteosarcoma therapy, surgical treatment is considered a standard method, being the most effective and offering the greatest chance of recovery $[16,17]$. Osteosarcoma treatment is mainly surgical, but radiotherapy and chemotherapy applications have also been described $[7,18,19]$. The preferred method is a high-dose methotrexate, doxorubicin, bleomycin, and dactinomycine chemotherapy, used only in patients with no distant metastases [16, 20-22].

As a non-epithelial tumour, osteosarcoma metastasises to lungs mainly via circulating blood [16]. Lymph node metastases are rare, and their elective removal is not recommended. Depending on the size of the lesion, surgical intervention includes a complete or partial laryngectomy, the latter characterised by a radical approach [15]. Some of the presented cases mentioned the necessity of performing complete laryngectomy in patients with a local relapse after previous conservative surgeries [8, 23, 24].

The aim of the study was to present a rare case of a patient treated for laryngeal osteosarcoma along with diagnostic complications.

\section{Case description}

Patient K.W., female, 58 years old was admitted to the Clinic of Otolaryngology and Laryngological Oncology, Ludwik Rydygier Collegium Medicum in Bydgoszcz, Nicolaus Copernicus University as an emergency for dyspnoea 

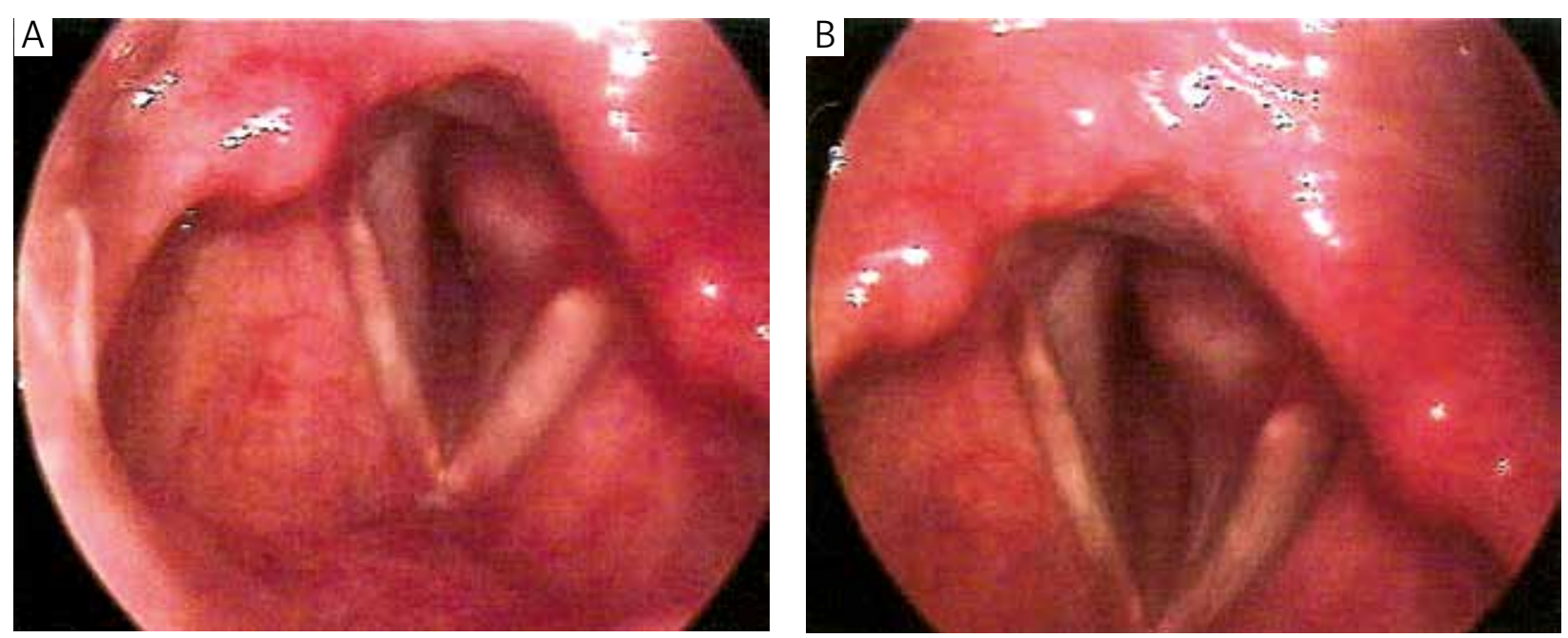

Fig. 1A, B. The figures illustrate images from the videostroboscopic examination of the larynx. A tumour narrowing the laryngeal lumen is visible

aggravating for six months due to laryngeal tumour in the left subglottic area.

Stroboscopic examination visualised a smooth-surfaced tumour in the left subglottic area of the larynx, covered with healthy mucosa. The left vocal fold was immobilised during phonation, and shortened in the anteroposterior dimension. No infiltration of other laryngeal structures or other anomalies was observed (Fig. 1 A, B).

Ambulatory $C T$ revealed a heterogeneous hyperdense lesion covering the left subglottic area, a tumour of $1.5 \mathrm{~cm}$ in diameter originating from thyroid cartilage, narrowed laryngeal lumen, and the lesion infiltrating the adjacent structures and penetrating $1.5 \mathrm{~cm}$ into the subglottis (Fig. 2 A, B).

After appropriate laboratory analyses, including radiology picture of the lungs, with no signs of any pathology and consultation, the patient was eligible for tracheotomy and microlaryngoscopy using the Kleinsasser method with tissue samples taken for histopathological analysis. Tracheotomy was performed under local anaesthesia using $1 \%$ lignocaine because of the possibility of dyspnoea, and this was followed by microlaryngoscopy under general an- aesthesia. Direct laryngoscopy revealed a spherical, thinwalled tumour in the left subglottic area, covered with healthy mucosa. The tumour diameter was approximately $1.5 \mathrm{~cm}$. Biopsy material was taken submucosally for a histopathological analysis. No postoperative complications were observed. The patient was discharged home after four days in good general condition, awaiting histopathology results.

Microscopic examination of the first biopsy within the tumour mass revealed spindle-shaped cells with hyperchromatic nuclei with areas of ossification and focally mononuclear inflammatory infiltration. The differential diagnosis based on the microscopic picture could correspond to degenerative changes in the course of chronic inflammatory processes.

After six weeks, the patient returned to the hospital for further treatment. The patient was admitted on that day and turned out to be eligible for surgical treatment in the clinic.

After anaesthesiological and internal medical consultations, as well as the normalisation of blood pressure and glycaemia, surgery using a U-shaped incision was
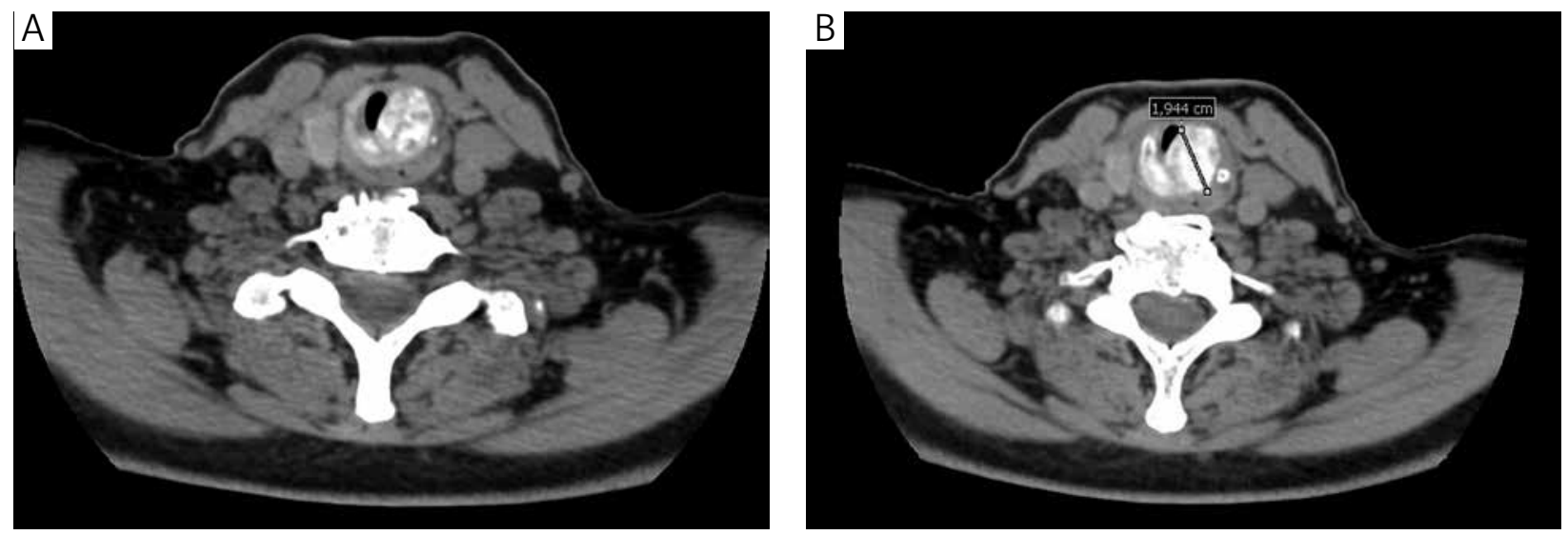

Fig. 2A, B. The figures present CT images of the larynx in horizontal plane with indicated tumour size 

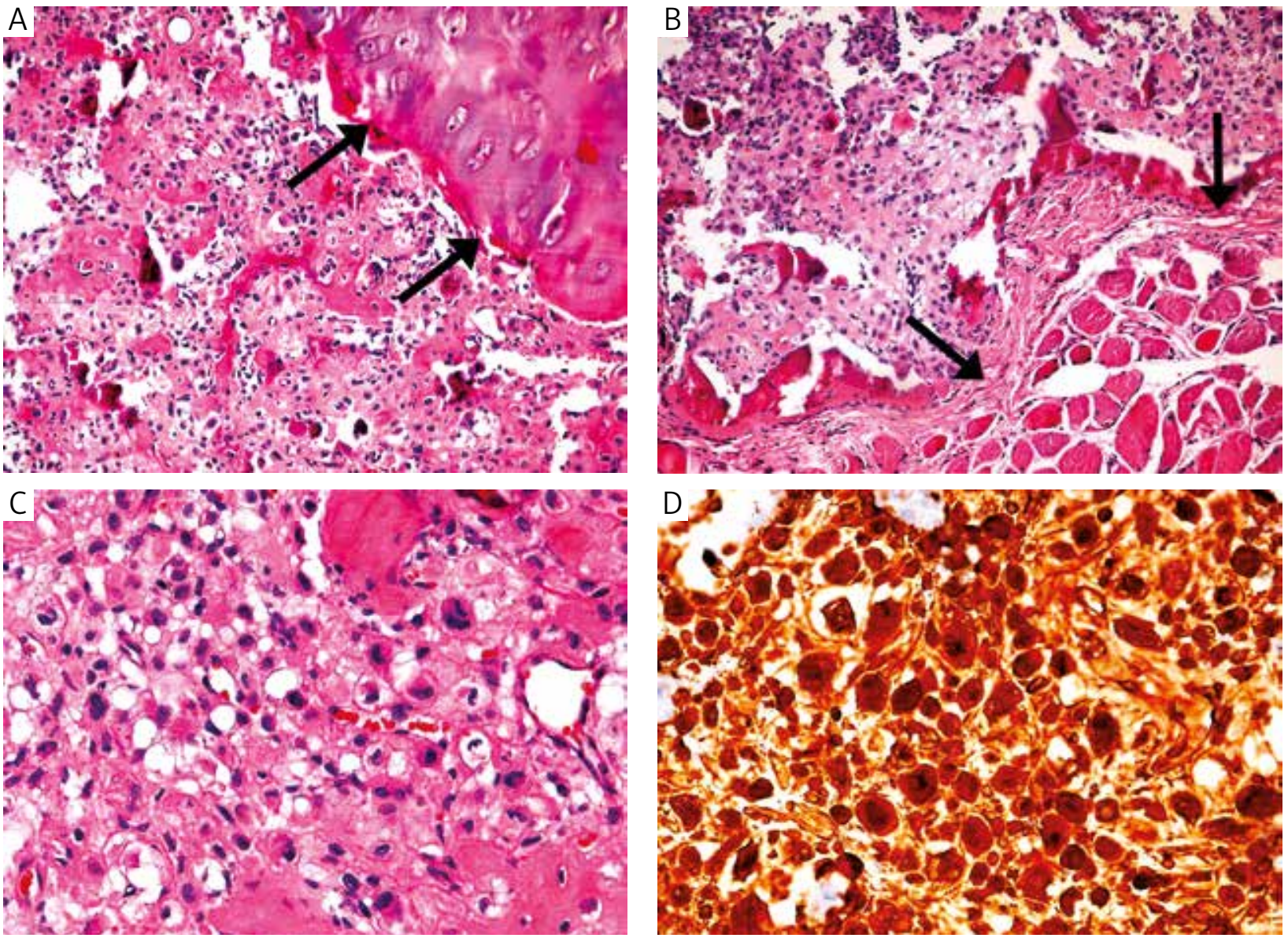

Fig. 3A-D. Microscopic image of osteosarcoma. Analysis of the slides was performed using $200 x$ total magnification (20x objective with $10 \times$ oculars). A - the arrows highlight osteosarcoma invasion into cartilage; $\mathbf{B}$ - the arrows highlight osteosarcoma invasion into surrounding muscles; $\mathbf{C}$ - areas of ossification and deposition of osteoid material; D - positive immunohistochemical staining for vimentin

conducted. The laryngeal bulla was incised in the middle line along the thyroid cartilage angle. Due to the observed infiltration of the cricoid and subtotal obturation of the subglottic area, a complete laryngectomy was performed. As no lymphatic node enlargement was observed, lymph nodulectomy was abandoned. The no. 8 tracheostomy tube was applied.

No postoperative complications were observed. The patient was discharged from hospital on the $10^{\text {th }}$ day after the surgery in good general condition.

A total laryngectomy specimen received after surgery consisted of the tumour $1.5 \times 1.5 \times 1 \mathrm{~cm}$ in size located in the left subglottic area. Grossly, on cross section, the tumour was dark brown and firm with cribriform pattern appearance. Microscopic examination revealed malignant mesenchymal tumour composed of polymorphic cells with hyperchromatic atypical nuclei and small areas of liquefactive tumour necrosis. There was an increased mitotic index. Extensive areas of ossification and deposition of osteoid material with bone formation were observed in different tumour parts (Fig. 3A, B, C). Histological examination also revealed extensive invasion into thyroid cartilage (Fig. $3 A$ ) and surrounding soft tissues (Fig. 3B). The tumour was positive for vimentin (Fig. 3D), and Ki-67-positive cells index was approximately $5 \%$ on average but focally up to $30 \%$.
The final diagnosis based on microscopic and macroscopic examination was osteosarcoma of the larynx.

The patient has been monitored in the Department of Otolaryngology for 22 months. During this time, there has been no local recurrence, distant metastases, or surgical complications.

\section{Discussion}

Osteosarcomas are a very rare group of non-epithelial tumours. Unlike osteomas and chondromas, osteosarcomas are considered as malignant tumours due to the high incidence of their relapses and metastases. Because of their blood-borne character, the metastases are usually located in the lungs. This type of tumour, similarly to other non-epithelial forms of tumours, are seen mostly in men and does not positively correlate with smoking and alcohol abuse. Significantly, laryngeal osteosarcoma is extremely rare in women [6].

Potential diagnostic difficulties in patients with laryngeal osteosarcoma may stem from a lack of possibility of obtaining suitable material for histopathological analysis. The tumour is hard, has a smooth surface, and is usually covered with laryngeal mucosa. Preoperative identification using microscopic imaging of tissue samples may not give a clear answer about the type of this rare tumour because 
the results may suggest the existence of laryngeal osteoma or chondroma alone.

As regards patient eligibility assessment, to obtain the patient's consent for a given type of surgical treatment a possible occurrence of malignancy has to be taken into account in some cases, despite the previous diagnosis of a benign lesion.

This paper presents the case of a woman with no history of nicotine addiction or alcohol abuse, in whom dyspnoea had been developing for at least six months. Despite previous deglutition disorders, the patient did not report to a laryngologist.

The short observation period in this case did not allow us to assess the patient's recovery, but the non-infiltrated surgical margins in the histopathology results with no lymphatic lesions or distant metastases enabled us to presume, concurring with many other authors, that the prognosis in this case should be good.

The authors declare no conflict of interest.

\section{References}

1. Batsakis JG, Solomon AR, Rice DH. The pathology of head and neck tumors: neoplasms of cartilage, bone, and the notochord. Head Neck Surg 1980; 3: 43-57.

2. Mark PA, Lupin AJ. Cancer of the larynx: the Northern Alberta experience. J Otolaryngol 1989; 18: 344-9.

3. Topaloglu I, Işiksaçan V, Ulusoy S, Sişman S. Osteosarcoma of the larynx. Otolaryngol Head Neck Surg 2004; 131: 789-90.

4. Berge JK, Kapadia SB,Myers EN. Osteosarcoma of the larynx. Arch Otolaryngol Head Neck Surg 1998; 124: 207-10.

5. Shimizu KT, Selch MT, Fu YS, Anzai Y, Lufkin RB. Osteosarcoma metastatic to the larynx. Ann Otol Rhinol Laryngol 1994; 103: 160-3.

6. van Laer CG, Helliwell TR, Atkinson MW, Stell PM. Osteosarcoma of the larynx. Ann Otol Rhinol Laryngol 1989; 98 (12 Pt 1): 971-4.

7. Remagen W, Löhr J, von Westernhagen B. Osteosarcoma of the larynx. HNO 1983; 31: 366-8.

8. Morawska A, Składzień J, Kurzyński M. Mięsaki krtani w materiale Kliniki Otolaryngologii w Krakowie. Otorynolaryngologia 2008, 7: 80-4.

9. Myssiorek D, Patel M, Wasserman P, Rofeim O. Osteosarcoma of the larynx. Ann Otol Rhinol Laryngol 1998; 107: 70-4.

10. Rydzewski B, Matusiak M. Osteosarcoma of the larynx. Otolaryngol Pol 2005; 59: 285-8.

11. Marioni G, Altavilla G, Marino F, Marchese-Ragona R, Lelli-Mami G, Staffieri A. Squamous cell carcinoma of the larynx with osteosarcoma-like stromal metaplasia. Acta Otolaryngol 2004; 124: 870-3.

12. Sprinkle PM, Allen MS, Brookshire PF. Osteosarcoma of the larynx. Laryngoscope 1996; 76: 325-33.

13. Pinsolle J, LeCluse I, Demeaux H, Laur P, Rivel J, Siberchicot F. Osteosarcoma of the soft tissue of the larynx: report of a case with electron microscopic studies. Otolaryngol Head Neck Surg 1990; 102: 276-80.

14. Patel SG, Meyers P, Huvos AG, et al. Improved outcomes in patients with osteogenic sarcoma of the head and neck. Cancer 2002; 95: 1495-503.

15. Sanaat Z, Mohammady G, Esmaili H, Emrani M, Dolatkhah R. Osteosarcoma of the larynx. Arch Iran Med 2009; 12: 499-502.

16. Eilber FR, Rosen G. Adjuvant chemotherapy for osteosarcoma. Semin Oncol 1989; 16: 312-22.

17. Dahm LJ, Schaefer SD, Carder HM, Vellios F. Osteosarcoma of the soft tissue of the larynx: report of a case with light and electron microscopic studies. Cancer 1978; 42: 2343-51.

18. Rossi RM, Landas SK, Kelly DR, Marsh WL. Osteosarcoma of the larynx. Otolaryngol Head Neck Surg 1998; 118 (3 Pt 1): 385-8.
19. Smith RB, Apostolakis LW, Karnell LH, Koch BB, Robinson RA, Zhen W, Menck HR, Hoffman HT. National Cancer Data Base report on osteosarcoma of the head and neck. Cancer 2003; 98: 1670-80.

20. Rossi RM, Landas SK, Kelly DR, Marsh WL. Osteosarcoma of the larynx. Otolaryngol Head Neck Surg 1998; 118: 385-8.

21. Meyers PA, Heller G, Healey J, et al. Chemotherapy for nonmetastatic osteogenic sarcoma: the Memorial Sloan-Kettering experience. J Clin Oncol 1992; 10: 5-15.

22. Arslan M, Orhan-Kizilkaya H, Yalcin B, Aksakal O, Uyanoglu A, Ozturk S, Erkal H, Kabukcuoglu F. Larynx osteosarcoma: case report. J BUON 2008; 13: 437-9.

23. Mottola G, Cascone AM, Cavaliere M, Angrisani B, Fiorillo G, Parente G, Volino F, lemma M. Osteosarcoma of the larynx: a case report. Cases J 2008; 1: 365.

24. Athré RS, Vories A, Mudrovich S, Ducic Y. Osteosarcomas of the larynx. Laryngoscope 2005; 115: 74-7.

\section{Address for correspondence}

\section{Piotr Sawicki}

Chair and Clinic of Otolaryngology

and Laryngological Oncology

Collegium Medicum in Bydgoszcz

M. Skłodowskiej-Curie 62/7

85-733 Bydgoszcz, Poland

e-mail: piotr.sawicki@cm.umk.pl

Submitted: 5.09 .2012

Accepted: $\quad 13.11 .2013$ 